03

\title{
Экспериментальное исследование ручейкового течения легкокипящей жидкости в мини-канале под действием потока газа
}

\author{
(C) В.В. Чеверда ${ }^{1,2}$, О.А. Кабов ${ }^{1,3}$ \\ ${ }^{1}$ Институт теплофизики им. С.С. Кутателадзе СО РАН, Новосибирск \\ ${ }^{2}$ Национальный исследовательский Новосибирский государственный \\ университет \\ ${ }^{3}$ Национальный исследовательский Томский политехнический \\ университет \\ E-mail: slava.cheverda@gmail.com
}

Поступило в Редакцию 8 сентября 2016 г.

Экспериментально исследовались разновидности режимов течения и построена карта 11 разновидностей режимов при течении ручейка диэлектрической легкокипящей жидкости в мини-канале под действием потока газа. Экспериментально установлено, что прямолинейное течение ручейка жидкости наблюдается в ограниченном диапазоне расходов жидкости, газа.

DOI: 10.21883/PJTF.2017.06.44401.16472

Под течением пленки жидкости в мини-канале понимается режим раздельного течения двухфазного потока, при котором смачивается вся поверхность подложки. Течение пленки жидкости под действием потока газа в мини-канале является эффективным решением для охлаждения микроэлектроники в наземных условиях и при невесомости. Принцип работы одной из таких систем описан в [1]. Одной из проблем при использовании микросистем с протяженными плоскими микро- и мини-каналами является большой перепад давления. Для эффективного охлаждения электронного компонента необходимо прокачивать достаточное количество жидкости и пара или газа, т.е. возникают большие энергозатраты [2]. Необходимо обеспечить движение пара или газа, а также жидкости с большими скоростями для обеспечения требуемой интенсивности теплообмена. При ручейковом течении смачивается только часть подложки. Использование ручейкового течения в системах 
охлаждения - многообещающее решение актуальной задачи интенсификации теплообмена благодаря наличию контактной линии смачивания с аномально высоким коэффициентом теплоотдачи по сравнению с пленочным течением [3]. При пленочном течении жидкость орошает всю подложку по ширине, в то время как при ручейковом течении жидкость орошает только часть подложки. При ручейковом течении в углах канала движется газ и тем самым обеспечивается снижение расхода жидкости, т. е. энергозатраты. Вязкость жидкости существенно больше вязкости газа, что обеспечивает уменьшение сопротивления при течении смеси и уменьшение перепада давления по каналу, а следовательно, уменьшение энергетических затрат на прокачку двухфазной смеси в микроканале.

По результатам экспериментов построены карты режимов ручейкового течения под действием силы тяжести жидкостей (триэтиленгликоля, а также водяных растворов спирта и глицерина) по наклонной пластине [4]. Карта разновидностей волнообразования при ручейковом течении водяных растворов глицерина и спирта построена в работе [5]. Математическая модель, описывающая течение ручейка легкокипящей жидкости (FC-72) под действием потока газа азота в мини- и микроканалах изложена в работе [6]. Эксперименты с ручейковым течением жидкости FC-72 под действием потока газа в условиях с изменяемым ускорением (параболические полеты) приведены в работе [7]. Исследовалось влияние параметров эксперимента на ширину ручейка. Эксперименты с ручейковым течением воды под действием потока газа в условиях с разным ускорением поставлены в работе [8]. При уменьшении значения ускорения ручеек воды становится менее устойчивым. В литературе отсутствует информация о карте режимов ручейкового течения жидкости FC-72 под действием потока газа или пара.

Цель работы состоит в построении карты режимов течения ручейка легкокипящей диэлектрической жидкости FC-72 в мини-канале под действием потока азота.

Рабочий участок состоит из текстолитовой пластины, на которую крепится пластина из нержавеющей стали - подложка. К текстолитовой пластине крепится рамка, которая сверху накрывается оптическим стеклом, образуя тем самым мини-канал. Газовый поток поступает в мини-канал на значительном расстоянии от входа жидкости. Ручейковое течение формируется частичным закрытием жидкостного сопла

Письма в ЖТФ, 2017, том 43, вып. 6 
высотой $150 \mu \mathrm{m}$. Начальная ширина ручейка после выхода из сопла составляет $10 \mathrm{~mm}$. Ручеек течет по подложке из нержавеющей стали с зеркальным алюминиевым покрытием (шероховатость $R_{z}=0.08 \mu \mathrm{m}$, плоскостность $1 \mu \mathrm{m}$ на $50 \mathrm{~mm}$ ), после чего двухфазная смесь эвакуируется из участка. Температура подложки измеряется несколькими термисторами, впрессованными в нее, и регулируется путем прокачки воды с контролируемой температурой через водяной теплообменник, а также электрическим нагревателем, прикрепленным к подложке снизу. Высота канала составляет $1.5 \mathrm{~mm}$ и регулируется металлическими вставками, установленными между оптическим стеклом и подложкой. Ширина прямоугольного миниканала составляет $40 \mathrm{~mm}$, а длина $120 \mathrm{~mm}$.

Наблюдения осуществляются с помощью высокоточной фазовой шлирен-системы [9]. Наблюдение деформаций и измерение ширины ручейка жидкости осуществляется на расстоянии $40 \mathrm{~mm}$ от жидкостного сопла. На этом расстоянии, как правило, наблюдается установление режима течения. Радиус области видения выбран как максимально возможный для фазовой шлирен-системы $-22.5 \mathrm{~mm}$. Экспериментальный стенд позволял поддерживать в ходе всего эксперимента одинаковую температуру подложки, газа и жидкости на входе в рабочий участок. Для анализа данных по структуре течения использовались числа Рейнольдса жидкости и газа $\left(\operatorname{Re}_{l}=Q_{l}\left(v_{l} a\right)\right), \operatorname{Re}_{g}=Q_{g} /\left(v_{g} b\right)$, где $Q_{l, g}$ - объемный расход жидкости или газа $\left(\mathrm{m}^{3} / \mathrm{s}\right), a-$ ширина мини-канала $(\mathrm{m})$, $b$ - ширина жидкостного сопла $(m), v_{l, g}-$ кинематическая вязкость жидкости или газа $\left.\left(\mathrm{m}^{2} / \mathrm{s}\right)\right)$.

По результатам экспериментов построена карта 11 режимов ручейкового течения в зависимости от расходов жидкости и газа при температуре подложки $40^{\circ} \mathrm{C}$. Наблюдались геометрические деформации (рис. 1) и деформации поверхности ручейка (рис. 2). Для удобства восприятия карты разновидностей ручейкового течения с геометрическими деформациями (рис. $3, a$ ) и деформацией поверхности ручейка (рис. $3, b)$ построены на разных графиках. Геометрические деформации делятся на следующие: $a-$ неустойчивое течение (при малом расходе жидкости ручеек начинает изгибаться, разделяется на два, распадается на капли); $b$ - сужающееся течение (ручеек сужается в результате интенсивного испарения легкокипящей жидкости, т.е. расхода жидкости не хватает, чтобы скомпенсировать это испарение, в этом случае равновесная ширина ручейка меньше начальной ширины ручейка на входе в мини-канал, равной ширине жидкостного

3 Письма в ЖТФ, 2017, том 43, вып. 6 


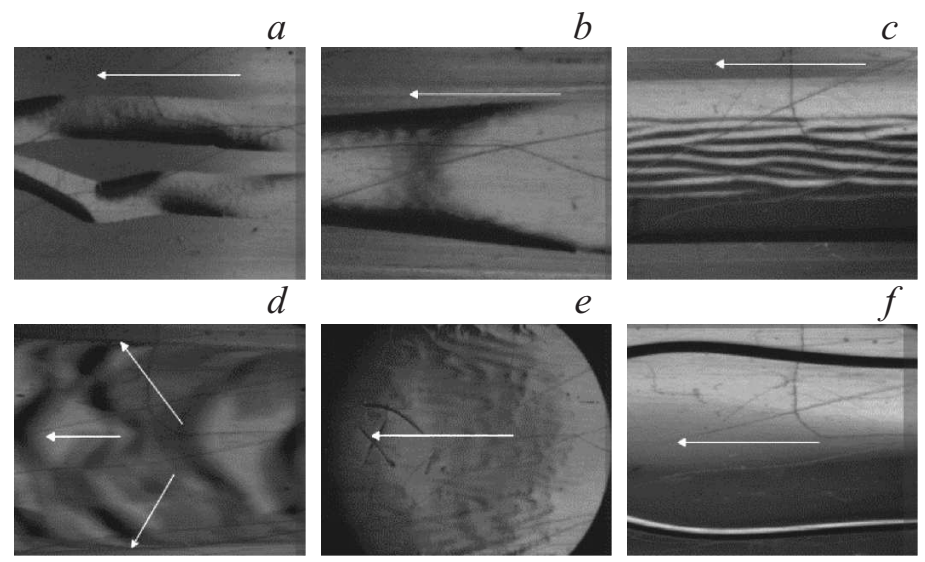

Рис. 1. Геометрические деформации ручейка легкокипящей жидкости (FC-72, фото), стрелками показаны направление течения и линия контакта ручейка и подложки мини-канала.

сопла); $c$ - прямолинейное течение с увеличением расхода жидкости (ширина ручейка в области видения изменяется не более чем на $5 \%) ; d-$ расширяющееся течение с дальнейшим увеличением расхода жидкости (ширина ручейка увеличивается по ходу течения более чем на 10\%); $e-$ пленочное течение как частный случай расширяющегося течения, при котором ручеек касается стенок миниканала; $f$ - инвертированное течение, если при пленочном течении ручейка происходит полное или частичное затопление миниканала жидкостью по ширине более чем на 10\%. Данное течение обусловлено недостаточно высоким расходом газа, чтобы проталкивать необходимое количество жидкости в мини-канале, а также хорошим смачиванием жидкостью боковых стенок и поверхности оптического окна мини-канала.

Деформации поверхности жидкости изучались в режиме три (рис. 3,a), когда осуществлялось практически прямолинейное течение ручейка жидкости. Течения с деформациями поверхности ручейка делятся на несколько видов: хаотическая рябь (рис. 2, a и 3,b-1) ширина образующихся структур незначительно отличается от их длины, характерный размер - несколько миллиметров; течение с вытянутыми

Письма в ЖТФ, 2017, том 43, вып. 6 


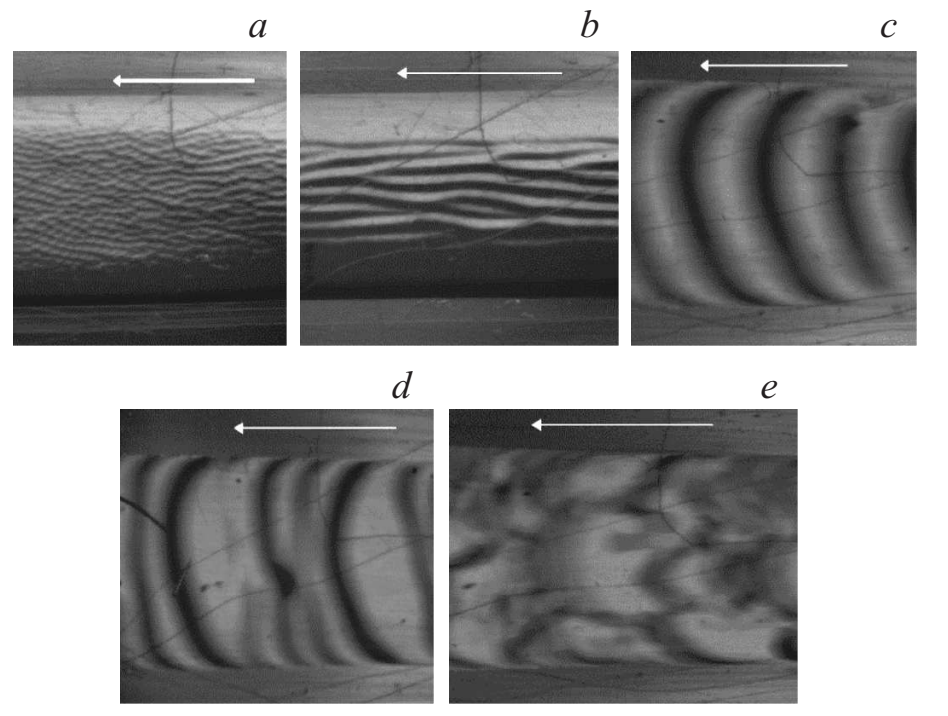

Pис. 2. Деформации поверхности ручейка легкокипящей жидкости (FC-72, фото).

по потоку деформациями в виде структур-жгутиков (рис. $2, b$ и $3, b-2$ ), длина волны структур поперек потока составляет несколько миллиметров, длина по потоку - несколько сантиметров, возникновение ряби и структур объясняется термокапиллярной природой в связи с интенсивным испарением [10]; сложная деформация в виде серповидной 2D-волны поперек течения (рис. 2, $c$ и 3, $b$-3), занимают всю ширину ручейка, волны наблюдаются совместно с деформацией в виде жгутиков; сложная деформация в виде солитонообразных волн (рис. $2, d$ и $3, b-4$ ), две большие и несколько малых волн между ними во всю ширину ручейка, наблюдается совместно с деформацией в виде жгутиков; сложная деформация в виде 3D-волн (рис. 2,e и $3, b-5$ ), наблюдается при высоких расходах газа, особенность - наличие деформаций, перпендикулярных потоку, ширина которых в несколько раз меньше ширины самого ручейка, наблюдается совместно с деформацией в виде жгутиков.

3* Письма в ЖТФ, 2017, том 43, вып. 6 

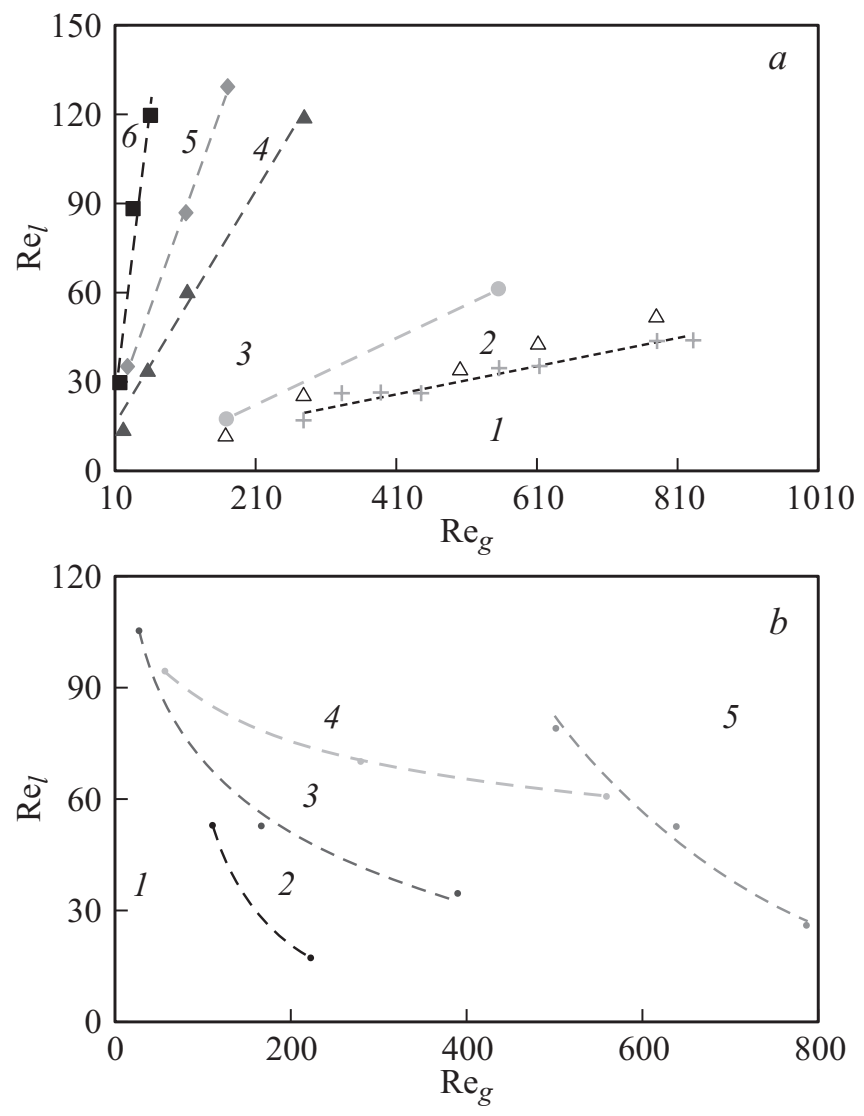

Рис. 3. Карта разновидностей деформаций ручейка легкокипящей жидкости (FC-72) при течении в мини-канале под действием потока газа азота для температуры подложки, газа и жидкости на входе в рабочий участок, равной $40^{\circ}$ C. $a-$ геометрические деформации: $1-$ неустойчивое течение, $2-$ сужающийся ручеек, 3 - прямолинейный ручеек, 4 - расширяющийся ручеек, 5 - пленочное течение, 6 - инвертированное течение. $b-$ деформации поверхности жидкости: 1 - рябь, 2 - структуры (жгутики), 3 - 2D-волны, 4 - солитонообразные волны, 5 - 3D-волны.

Письма в ЖТФ, 2017, том 43, вып. 6 
Таким образом, эксперименты показали, что рабочие параметры (расходы жидкости и газа) существенно влияют на ручейковое течение: существует ограниченная область, в которой течение ручейка осуществляется с примерно постоянной шириной (область 3 , рис. $3, a$ ).

Именно эта область удобна для проведения исследований гидродинамики и волновой структуры ручейковых течений. Этот режим течения, также может быть использован для практических приложений, т.е. в теплообменных устройствах. Экспериментально показано, что поверхность жидкости наблюдается всегда с деформациями. Можно выделить два основных класса волн: 1) с волновым фронтом, ориентированным вдоль течения, вызваны термокапиллярной неустойчивостью и испарением (информация о природе данной неустойчивости на поверхности пленки приведена в [9]); 2) с волновым фронтом, ориентированным поперек течения, вызваны гидродинамической природой [5]. Установлено, что в широком диапазоне числа Рейнольдса жидкости и газа эти два класса волн сосуществуют. Установлен переход от ручейкового течения к пленочному без разрывов жидкости на достаточно коротком участке по длине, равном ширине канала. Таким образом, определены предельные режимы для течения ручейка в канале.

Исследования карты режимов течения выполнены за счет гранта РНФ 14-19-01755. Настройка и адаптация фазовой шлирен-системы осуществлялась при поддержке проекта Российского фонда фундаментальных исследований (РФФИ_мол_а 14-08-31515).

\section{Список литературы}

[1] Kabova Yu.O., Kuznetsov V.V., Kabov O.A. // Microgravity Sci. Technol. 2008. V. 20. Iss. 3-4. P. 187.

[2] Kabova Yu.O., Kuznetsov V.V., Kabov O.A. et al. // Int. J. Heat Mass Transfer. 2014. V. 68. P. 527.

[3] Stephan P., Brandt C. // Heat Transfer Eng. 2004. V. 25(3). P. 78.

[4] Schmuki P., Laso M. // J. Fluid Mech. 1990. V. 215. P. 125.

[5] Alekseenko S.V., Bobylev A.V., Kharlamov S.M. et al. // Abstracts of papers of 14th Int. Symp. on Applications of Laser Techniques to Fluid Mechanics. Lisbon. Portugal. 2008.

[6] Kabov O.A., Bartashevich M.V., Cheverda V. // Int. J. Emerg. Multidisciplin. Fluid Sci. 2010. V. 2(2-3). P. 161.

Письма в ЖТФ, 2017, том 43, вып. 6 
[7] Cheverda V., Glushchuk A., Queeckers P. et al. // Microgravity Sci. Technol. 2013. V. 25 (1). P. 73.

[8] McAlister G., Ettema R., Marshall J.S. // J. Fluids Eng. 2005. V. 127. P. 257.

[9] Joannes L., Dubois F., Legros J.C. // Appl. Opt. 2003. V. 42 (25). P. 5046.

[10] Kabov O.A., Zaitsev D.V., Cheverda V.V. et al. // Exp. Therm. Fluid Sci. 2011. V. 35 (5). P. 825. 